\title{
Spatial Knowledge Acquisition in the Process of Navigation: A Review
}

\author{
Negar Ahmadpoor ${ }^{1 *}$, Sina Shahab ${ }^{2}$ \\ ${ }^{1}$ School of Architecture and Built Environment, University of Nottingham, Nottingham, UK \\ ${ }^{2}$ School of Geography and Planning, Cardiff University, Cardiff, UK \\ Email: *laxna10@nottingham.ac.uk
}

How to cite this paper: Ahmadpoor, N., \& Shahab, S. (2019). Spatial Knowledge Acquisition in the Process of Navigation: A Review. Current Urban Studies, 7, 1-19. https://doi.org/10.4236/cus.2019.71001

Received: January 4, 2019

Accepted: February 9, 2019

Published: February 12, 2019

Copyright (c) 2019 by author(s) and Scientific Research Publishing Inc. This work is licensed under the Creative Commons Attribution International License (CC BY 4.0).

http://creativecommons.org/licenses/by/4.0/

\begin{abstract}
Spatial cognition has become an increasingly important area of study since it represents a major type of human knowledge with considerable practical significance. The general assumption is that people's spatial knowledge forms people's spatial behaviour, such as navigation, in the environment. However, there are some critical issues within this area, including: how such knowledge is represented and organised, the mechanisms by which it is activated, and the elementary and higher-level cognitive processes that function upon the knowledge base to produce new knowledge as well as the factors that are influential on acquiring spatial knowledge. The theories regarding spatial knowledge acquisitions have attempted to address these issues. This paper discusses these issues by reviewing the literature. As such, the paper firstly provides the research background on spatial knowledge acquisition and the theories of spatial knowledge development. Secondly, the paper debates the main factors affecting acquiring and forming knowledge about the environment. In doing that, the effects of two main factors are discussed: 1) the means of spatial knowledge acquisition (direct experience, physical map, and mobile maps), and 2) the role of different properties of physical environment.
\end{abstract}

\section{Keywords}

Spatial Knowledge, Navigation, Physical Environment, Spatial Design Disciplines

\section{Introduction}

We as humans live in space and this tends to be a fact which does not require us to think about it, however, living in a space entails people to continuously interact with space and process the received information from the surroundings. 
People move around, perceive the environment around them, acquire knowledge about it, store it to their minds, modify the information collected, and use it when it is needed, either consciously or unconsciously (Ahmadpoor \& Heath, 2018). Examples of knowledge about space are the name of places, distances and direction between the places, and the relational organisation between places. People use such spatial knowledge to get from home to work, to plan their travels between different places, to give navigational directions to others. This knowledge which is stored in the brain, determines people's behaviour in the environment. In other words, people's behaviour is generated by people's spatial knowledge or mental representation of the physical environment. There are many factors that affect spatial knowledge acquisition (Appleyard, 1969; Golledge et al., 2000; Dogu \& Erkip, 2000). This paper categorises these factors into internal and external factors. Internal factors, such as individual's familiarity with the place and individual characteristics (gender, age, education, etc.), are referred to the factors that are internal to individual's body and can be different from one person to another. External factors, such as physical environment and the means of navigation, are termed to the factors that are external to individual's body, and people can't have much control over them during the process of navigation.

This paper reviews the theories on spatial knowledge acquisition and particularly discusses the effects of the external factors, namely, means of spatial knowledge acquisition and physical environment, on spatial knowledge. Means of spatial knowledge acquisition are the methods that individuals use to acquire spatial knowledge during their navigation. It can be either direct experience of physical environment, or receiving the information from different media, such as physical maps, pictures, and mobile maps, or combination of both methods. Regarding the means of navigation, more recently, the emergence of location-based services and the widespread daily use of mobile navigation systems (Speake, 2015) as a means of spatial knowledge acquisition have had a significant impact on everyday navigation processes for many people. A common focus of many studies is placed upon the effects that using these systems might have on the user's understanding of place, and the extent to which they acquire knowledge about the environment on the basis of the information provided (Ahmadpoor \& Heath, 2017). These studies will be discussed in this paper. Another external factor that affects spatial knowledge acquisition is physical environment. Physical environment can facilitate people's spatial knowledge acquisition, learn the environment, and affect people's memory of the place. For example, some places are easier to be spatially comprehended and some others are more challenging to be understood. This can be contributed to spatial and physical features of the physical environment (Golledge, 1999). This paper firstly provides the research background on spatial knowledge acquisition and the theories of spatial knowledge development. Secondly, the paper discusses the main factors affecting acquiring and forming knowledge about the environment. In doing 
that, the effects of two external factors are discussed: 1) the means of spatial knowledge acquisition (direct experience, physical map and mobile maps), and 2) the role of different properties of physical environment.

\section{Spatial Knowledge Acquisition}

The ultimate process of acquiring spatial knowledge that happens in people's everyday lives are referred to cognitive mapping (Downs \& Stea, 1973). This knowledge which is stored in the brain, controls people's behaviour in the environment. In other words, people's behaviour is not merely based on the physical environment but on people's spatial knowledge or mental representation of the physical environment. This has been a major premise in behavioural geography, which emerged in 1960s (e.g. see Golledge et al., 2000). Since then, many researches from different disciplines have studied the concept of mentally represented environments. The term cognitive map has been remained as a general term used to explain the cognitive process involved in the acquisition, representation, and processing of information about real physical environments. Nonetheless, researchers in different disciplines have used different terms such as mental maps, mental image, and mental pictures, which have the same meaning as cognitive maps (Downs \& Stea, 1973). The term cognitive map is widely used in several disciplines such as environmental psychology, social psychology, anthropology, geography, cognitive studies, city planning, urban design, and architecture. Cognitive maps are incomplete, in segments, and distorted internal representation of the physical environment. They keep getting updated; so at one occasion, a cognitive map is just a snapshot of the state of spatial knowledge and will get changed as time goes on. However, a cognitive map, according to cognitive psychology, is not a "picture in the head." A cognitive map is different from a picture as it does not have all the details, as it can be distorted, and it is segmented into meaningful pieces (Anderson, 1996). Moreover, a cognitive map is also a "compact orderly collection of knowledge. It contains more information than one can generally conceive at once, thus permitting one to anticipate, to react, to consider next possible events" (Kaplan \& Kaplan, 1982: p. 63). Also, cognitive maps can help with decision making even if lots of information are missing. Furthermore, they are known to be essential contributors in the adaptive process of spatial decision-making. They are used to lead spatial behaviour, such as way finding in the environment (Kitchin, 1994). Evans (1980) argued that cognitive maps represent spatial organisation between places, relative distances, orientation, and cardinal directions of different parts. Downs and Stea (1973) stated that cognitive maps also contain the information about the hierarchical arrangement of places in the environment with regards to size and relative distance. He also stated that cognitive maps have the information about the degree of interconnectedness between places, and although they are not cartographic, experientially hold some map-like qualities. A good and accurate cognitive map facilitates the subject's movement and navigation within the actual en- 
vironment.

Acquiring spatial knowledge from large-scale environments (e.g. urban environments) has been investigated by various researchers. Ittelson (1973) deliberated the characteristics of large-scale environments and stated that perception of large-scale environments should be concerned differently from traditional object perception. People cannot comprehend the spatial layout of large-scale environments in its entirety from one viewpoint; as a result, people should move within the environment and explore it, and integrate the spatial knowledge acquired from different viewpoints and movement experiences. Therefore, their spatial knowledge develops over time as they experience the environment more often. These spatial knowledge or cognitive maps become more accurate over time (Golledge, 1999). Spatial knowledge development in a "new" large-scale environment is called spatial microgenesis, whereas the spatial knowledge development across life-span is referred to ontogenesis (Ishikawa \& Montello, 2006).

What characterise the most theories of spatial knowledge development is the "stage" progress and generic "parallelism" that happen between different kinds of development; microgenesis and ontogenesis are two kinds of it (White, 1983). These theories believe that there is a steady developmental progress toward an increased level of abstractness, flexibility, integration, and perfection. The stages of spatial knowledge development are hierarchically organised, and each stage is qualitatively different from the other one. The later stages are formed upon and surround the earlier stages (Mandler, 1988). One of the fundamental theories for spatial knowledge development is Piaget's developmental theory. Piaget and Inhelder (2013) discussed the spatial knowledge development of children in terms of three stages of spatial relations, namely, topological, projective, and Euclidean. Regarding topological knowledge, it is concerned with qualitative relationships, such as, proximity, separation, order, enclosure, and continuity. Projective knowledge contains the spatial relations tied to a specific viewpoint, and Euclidean knowledge compasses metric information, such as distances, and directions. Piaget and Inhelder argued that children, in their experiments, initially understood the environment topologically, and projective and Euclidean knowledge gained, in apparel, but in a stage later. However, it took longer that Euclidean knowledge get to the state of equilibrium. Hart and Moore (1973) expanded on this theory and characterised the space in regards to three kinds of frame reference, namely, egocentric, fixed, and coordinated. They explained that the knowledge in children develop from an egocentric space into allocentric space, meaning, a space which is concerned with a specific orientation into a space in which different scenes from different viewpoints are connected. Similar to Piaget and Inhelder, they worked mainly on ontogenesis knowledge development, but briefly took on microgenesis development.

Developing these arguments, Siegel and White (1975) suggested a framework to explain microgenesis development of spatial knowledge. This framework 
proposes that spatial knowledge development occurs in three stages of landmark knowledge, route knowledge, and survey knowledge. Landmark knowledge is referred to knowledge of discrete object, locations, scenes that are salient in the environment to the traveller. They say that "landmarks are unique pattern of perceptual events at a specific location; they are predominantly visual for human adults; they are the strategic foci to and from which one travels" (225). Accordingly, landmarks cite a specific geographical location. For instance, "the intersection of Broadway and 42nd Street is as much a landmark as prudential centre in Boston, the Eiffel tower in Paris, or the billboard advertising Winston cigarette" (23). They also added that conscious knowledge of where we are going to as landmark knowledge (e.g. we are going to the park or we are coming from the office). Also, landmarks do classify the beginnings and endings and also are employed as intermediate course-maintaining devices. Because this helps with having correct navigational direction in the environment (Gladwin, 1972).

Regarding route knowledge, this stage of knowledge contains sequences of landmarks and related navigational decision (e.g. go straight for two blocks and turn right at that landmark). Siegel and White (1975) stated that at the beginning of the journey, if one knows that $s /$ he is going to see a particular landmark or sequence of landmarks, the one has a route. If the targeted landmarks did not happen, the question from the subject is what am I doing here? Am I on the correct way? Based on their research, "the space between landmarks is at first 'empty', and then gains 'scaling' with accumulative experiences” occurred over time in the environment (p. 29). According to this framework, landmarks and routes are known as necessary elements for cognitive representations that allow way finding to happen. Routes can give shape to the knowledge representative of environment. In order to have survey knowledge formed, landmarks and routes should be interconnected with each other, even those that are not directly connected. To summarise their theory, they put it up that people's development of spatial knowledge occur in three different stages: landmark knowledge, route knowledge, and survey knowledge. In line with Montello (1998) and Ishikawa and Montello (2006), this paper refers to this framework, as the dominant framework. The terms (landmark, route, and survey knowledge) have been used in to the dominant framework can be tracked back to the work done by Shemyakin (1961). He identified the differences between route knowledge representation and survey knowledge representation through comparing the sketch maps drawn by children from a familiar place. He pointed out that the route knowledge was developed earlier than survey knowledge. He stated that the survey-map type of representation cannot be formed unless a certain amount of route-map type of representation is accumulated. He added that these two types of knowledge representation exist not only in children, but also in adults.

The dominant framework is a reminiscence of Lynch's theory which recognised five elements of physical environment (i.e. landmarks, nodes, routes, edges, and district) which are in correspondence with spatial knowledge (Lynch, 
1960). Having said this, the developmental stages of dominant framework have not received substantial empirical supports. Also, dominant framework drew an analogy with ontogenesis and explained that adults, in a new environment, do not acquire metric knowledge (knowledge of distance) in the early stages (i.e. landmark knowledge, and route knowledge), unless they explore the area over time and accumulate experiences with the environment. In contrast, other researchers have shown that people with minimal exposure to a new environment gain metric configurational knowledge that can perform a navigational task (e.g. orientation, making decision at the decision points, taking shortcuts, going back directly to the start point, estimating the distances) at least better than chance (Klatzky et al., 1990; Landau et al., 1981; Landau et al., 1984; Leonard \& Newman, 1967; Loomis et al., 1993; Rieser et al., 1980; Sadalla \& Montello, 1989; Worchel, 1951). These works, based on their empirical studies, argue that people can comprehend the distances and orientation accurately with minimum experience in a new environment, while the dominant framework consider it as impossible without accumulated experiences in the environment.

Moreover, in inconsistent with other research mentioned above, the dominant framework is very descriptive and does not provide the details of spatial knowledge developments in details. In a generic way, it only describes that the spatial knowledge progress from landmark knowledge, to route knowledge and then survey knowledge, however, it does not elaborate the fact that how much effort or time is needed for going from one stage to another. For instance, it says that landmarks are first learned and then a sequences of landmarks are learnt, but do not provide any details about the interval between the two states, or says that "landmarks and routes are interrelated as a function of repeated experiences" (Siegel \& White, 1975: p. 30), but it does not specify how much experience is needed (Blades, 1991), which gives criticisms to the dominant framework for being descriptive and imprecise.

Acknowledging these gaps within the dominant framework, Montello (1998) puts forward a new framework to explain the spatial knowledge development. This framework opposes the unrealistic assumptions of the dominant framework that no metric knowledge being formed at the early stages of spatial knowledge, and states that "metric configurational knowledge begins to acquire on first exposure to a novel environment" (Montello, 1998: p. 146). In Montello's framework, there is a continuous (quantitative) development rather than discrete (qualitative) progress. A few other researchers made similar points, but not as detailed as Montello did. Evans (1980) said that "the operational distinction between these Piagetian stages may reflect scalar differences instead of distinct stages of spatial cognition" (p. 275). Hirtle and Hudson (1991) asserted that there are not discrete knowledge states, however, there is a continuum between route and configurational knowledge. McDonald and Pellegrino (1993) pointed out that "different type of spatial knowledge [landmark, route, survey knowledge] maybe required to different degrees, they are not necessarily acquired in 
the developmental order, and... in natural setting, some types of spatial knowledge may not be acquired at all” (p. 54).

Studies have examined the spatial development of people in a new environment. Most of them used sketch map drawing as a method that externalises the spatial knowledge conceived by people. This method became popular and was broadly used after Lynch's work (1960), which used this method in his research, for example, see (Appleyard, 1970; Beck \& Wood, 1976; Devlin, 1976; Humphreys, 1990; Moore, 1974; Murray \& Spencer, 1979; Spencer \& Weetman, 1981; Pearce, 1977; Pocock, 1976; Walmsley \& Jenkins, 1992). These studies counted the number of elements (landmarks, routes, nodes) drawn on the sketch maps, or classified the sketch maps based on their style (e.g. spatial, sequential) or the degree of their complexity (e.g. chain, branch, scattered, mosaic, and pattern). Also, some of them tested the association between these characteristics of the sketch maps, and the characteristics of the individuals who drew these maps. Among these characteristics, one had received more attention was the degree of people's familiarity or experiences with the physical environment. In order to test the effect of familiarity on people's spatial knowledge, they examined the spatial knowledge of people with different length of residence, such as local residents and short-term visitors. The studies did not show a consistency in results; in some studies, the most dominant elements were landmark and spatial style for the style of the sketch maps, whereas in some other studies, the main dominant element was route and the style of the maps were sequential. These differences are discussed and referred to several reasons: 1) differences in the degree complexity of the study area, 2) the difficulty in essence of classifying the sketch maps, 3) the lack of control over the experiments in terms of tools (e.g. maps and verbal description). Some of the researchers (e.g. Murray \& Spencer, 1979) indicated that these differences in sketch map drawing could be results of individual abilities in drawing. Although some of these researchers elaborated the spatial knowledge development based on the sketch maps (e.g. Moore, 1974), their results did not show a conclusive conclusion.

Some interesting results were found in analysing the sketch maps; the number of elements depicted on the maps increased when familiarity increased. Beck and Wood (1976) and Devlin (1976) noticed that when familiarity raised, the basics of the sketch maps did not change very much, but included more details. This shows that people learn more landmarks and paths over time to fill in the sketch maps. However, these results did not show anything regarding the accuracy of the drawn sketch maps. Evans et al. (1981) studied the progress in accuracy of spatial knowledge in the same people for after two weeks, and 10 months then. They found that ordinal accuracy did not change between two times, but Euclidean accuracy improved. In this sense, Golledge (1978) puts forward a conceptual framework, which is known as anchor point theory, which explains the spatial knowledge development based on a "filling-in" process in sketch maps. He specified that people initially acquire spatial knowledge from the areas 
that they often use, such as their home, work, the café they use most, and when familiarity increased, they start gaining spatial knowledge about the surrounding area. Accordingly, people's spatial knowledge about the area is first skeletal including the fundamental nodes and paths, and as time goes on it become more detailed with spaces in between filled in with details.

A group of researchers focused on cross-sectional studies examining people's spatial knowledge in relation to their level of familiarity and experience within the physical environment; they have tested spatial knowledge of people with different length of residency in a specific neighbourhood. Herman et al. (1979) compared the spatial knowledge of three different groups according to the length they have lived in the university campus that they studied. The three groups were: 1) three weeks, 2) three months, and 3) six months. They evaluated landmark knowledge, route knowledge, and survey knowledge of their participants by asking them: 1) to recall and match the buildings of the campus, 2) to give direction between two pairs of buildings on campus, 3) to rank order the distances of straight-lines between two pairs of buildings. For the first two tasks, the three months group performed better than three weeks group, however, three months and six months groups did not differ. For the third task, they merely compared the three weeks and three months groups and noted that the latter had more detailed spatial knowledge than the former. They came to this conclusion that the participants acquired accurate landmark, route, and survey knowledge only after three weeks, and then their knowledge become more detailed in the next two months, but does not differ much after that. However, there are two things to be considered in interpreting the results of their study; first, the amount of experience for each group was not controlled (simply the length of residency in a neighbourhood cannot be equivalent to their amount of their experience there);second, the way that those groups experienced the site was not controlled, some of them might experience the site solely on direct experience, and some might use maps (the tools used in navigation affect spatial knowledge acquisition, e.g. see (Thorndyke \& Hayes-Roth, 1982; Ishikawa et al., 2008).

Some studies have experimentally tested the development of accuracy of spatial knowledge; one of which is the study by Gärling et al. (1981). They had participants that travelled a route either on foot or car, they were then required to do a series of tasks, naming landmark in the order they saw them, estimating the distances and direction between landmarks. They were asked to repeat the route travel and navigational tasks in three sessions. They came back for the second session in 6 to 8 days; it was found that, in the second session, participants ordered the landmarks almost perfectly comparing to the first session, also the accuracy in direction and distance estimation increased after the first session. Also, it was noted that the participants who travelled by car acquires spatial knowledge quite faster than participants who walked.

Also, Herman et al. (1987) tested the development of accuracy of spatial 
knowledge in three different age groups; 8 year-old group, 11 year-old group, and 19 year-old group in a condition that they travelled a route by car. Their spatial knowledge was assessed by asking them to estimate the directions and distances. Travelling and estimation tasks were repeated in three sessions and the results were compared. They found that direction estimation was improved in the 11 year-old group and 19 year-old group from first session to the second session. Nevertheless, this improved for 8 year-old group from the second session to the third session. However, the distance estimation improved only in 19 year-old group.

\section{The Main Factors Affecting Spatial Knowledge Acquisition}

As discussed above, according to the theories regarding the spatial knowledge development, there are, at least, four main factors involved in forming spatial knowledge or cognitive maps: individual characteristics, the degree of familiarity with the physical environment, physical environment itself, and the means of spatial knowledge acquisition. These factors can be categorised into two external and internal factors. Factors, such as physical environment, and the means of spatial knowledge acquisition, that are external to individual's body are referred to external factors. Individual characteristics and the degree of familiarity with the physical environment that are internal to individual's body are termed to internal factors (Figure 1). As Golledge (1987) stated, cognitive mapping development is a way to structure, make sense of, and confront with the complexities of environments that are external to brain. The development of cognitive mapping has a robust relationship with environmental and individual factors. Indeed, the degree of familiarity with the environment is an important factor in

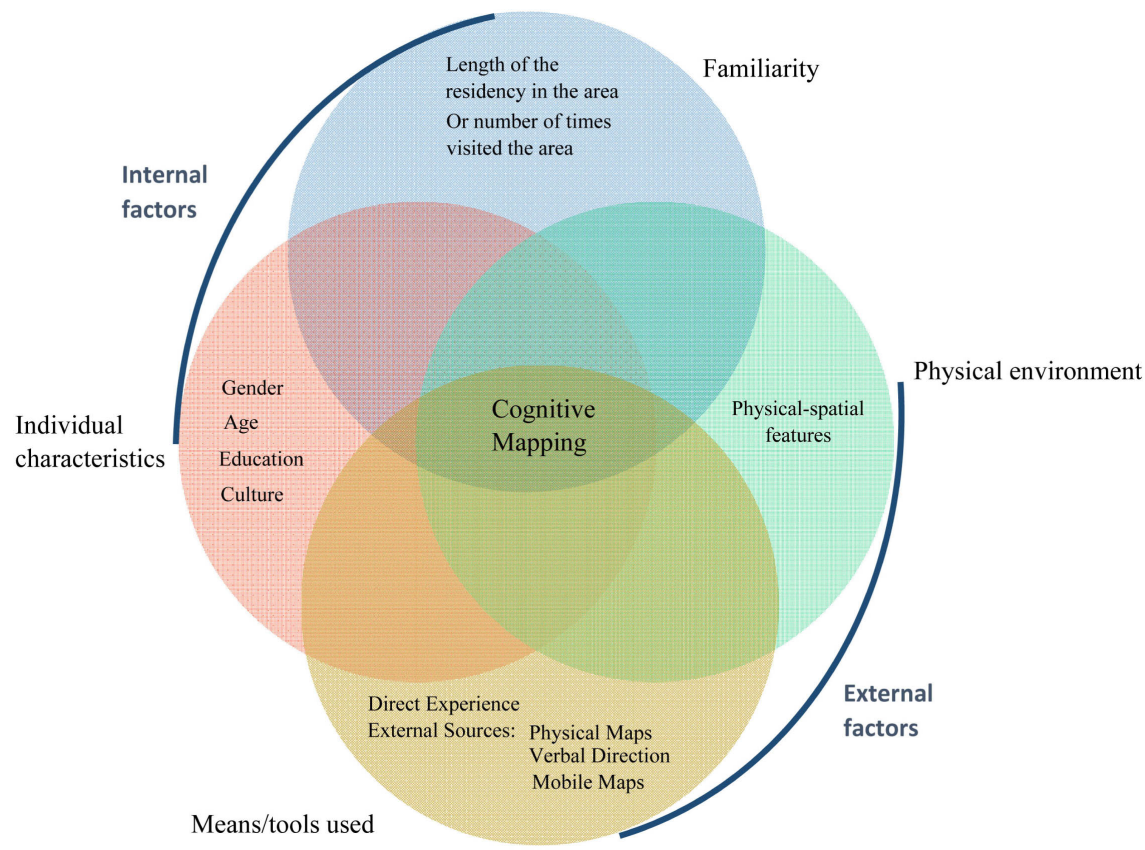

Figure 1. The main factors in cognitive mapping-authors' diagram. 
human cognitive mapping development. As it was mentioned above, in the theories of spatial knowledge development, as people get to know an environment better, they will conceive a better cognitive map of it. Moreover, individual characteristics and abilities have an essential role in this process. Some people can find the destinations and directions easily, while others get lost so often. Finally, the way with which people acquire spatial knowledge is an important factor; people may experience an environment directly, or use other sources, such as physical maps, mobile maps, or a combination of them.

\subsection{The Means of Spatial Knowledge Acquisition}

According to Haq and Girotto (2003), there are two means to acquire and develop spatial knowledge; one is direct experience of the physical environment, and the second is receiving the information from external sources by being exposed to different media, such as physical maps, pictures, and mobile maps. In the navigation process, in order to get to a destination successfully, three stages need to be occurred: 1) people first need to be able to orient themselves in the environment (i.e. they need to know where they are and in which direction they are heading); 2) Then, they need to plan a route to get them to their destination with the knowledge of where their destination is located; and 3) Finally, they need to execute the planned route to their destination. In all these three stages in navigation, people refer to the stored spatial knowledge/cognitive map in their mind, or use the navigational aids such as maps or combine the both (see Figure 2).

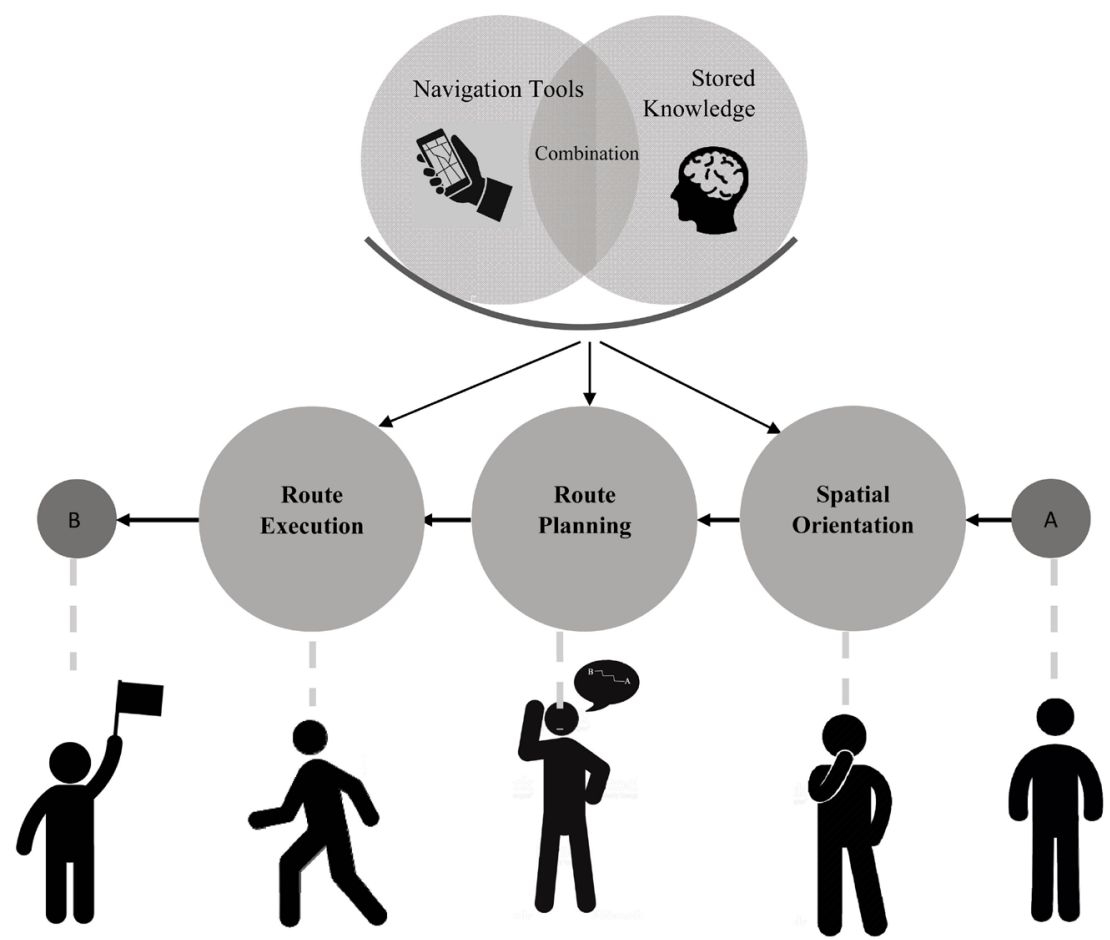

Figure 2. Schematic explanation of stages involved in navigation-authors' diagram. 
There have been different navigational aids that people use. One of the popular ones is physical maps; they have traditionally had considerable roles in conveying spatial information and guiding people through the environment. However, with the recent advent of advanced information technologies, devices (such as mobile devices and cars) equipped with GPS (Global Positioning System) receivers, such as GPS-based navigators, have become promising tools in guiding people, at least where accurate readings of satellite signals are possible (Shoval \& Isaacson, 2006).

Regarding learning the maps, research has shown that maps can help with configurational understanding of the environment, compared to direct experience of the space. This happens because maps, somehow suggest people the abstract form of the environment, which is very much close to the abstract format of cognitive maps. Having said that, knowledge acquired from maps have a robust relationship with the orientation in which the maps were observed (i.e., orientation-specific), so it is effortful to imagine views from different perspectives (Roskos-Ewoldsen et al., 1998; Sholl, 1988; Thorndyke \& Hayes-Roth, 1982). Also, research has demonstrated that using maps in the environments require people to understand the relationships between the map, the surrounding environment, and the self. Liben et al. (2002) showed with their experiments that, doing all these several tasks together is not easy for children and even for adults.

Regarding the other types of navigational aids, different formats of spatial information presentation have been developed, such as verbal navigational directions, static maps, interactive maps, 3-D visualisations, animations, and virtual environments (e.g. see Montello et al., 2004). Researchers have compared the effectiveness of different presentation formats. For example, Streeter et al. (1985) tested the effectiveness of a route map vs. taped verbal instructions for guiding drivers in an unfamiliar environment. They noted that the group used carefully constructed verbal instructions performed better than the route map in travel time and distance and the number of navigation errors. Coors et al. (2005) compared 2-D maps and 3-D visualisations formats of a route instruction on mobile devices. The 2-D maps group located their positions and reached destinations faster than 3-D format group. Dillemuth (2005) compared an aerial photograph and a generalised map as representations for a handheld navigational device. They noted that the group used generalised map had faster travel speed and fewer navigation errors than the aerial photograph group. Despite these past attempts in the literature, more empirical research on the effectiveness of different types of navigational aids is still needed.

\section{Spatial Knowledge Acquisition by Mobile Maps}

Research has shown that mobile navigation systems are not very effective tools in helping people to acquire spatial knowledge (Ahmadpoor \& Heath, 2015). Münzer et al. (2006) compared the spatial knowledge acquired by people who 
used a hand-held computer-based assistance (which could indicate the to-be adopted direction from the current position of the user) to those who used physical maps for navigation in a real environment (in a zoo). As they pointed out, depending on the learning experience, people acquire different forms of knowledge of the physical environment. Route knowledge is the knowledge of places/landmarks and the routes that attach them, and survey knowledge specifies an understanding of the spatial relationships between locations. Most people first acquire route knowledge, when exploring an environment merely by navigation (i.e. without any assistance such as a map). Münzer et al. (2006) tested their participants' route knowledge and survey knowledge of their study site. They found that participants who used physical maps presented perfect route knowledge and good survey knowledge. However, computer assisted participants were not very successful in acquiring route and survey knowledge; they showed poor survey knowledge and nearly good route knowledge. Likewise, Krüger et al. (2004) studied the effects of mobile pedestrian navigation systems on the development of route and survey knowledge acquired by people in an experiment. They illustrated the similar results to Münzer et al. (2006) and reported that people who used mobile maps for navigation could not build up a strong survey knowledge of the study site. In another study, Ishikawa et al. (2008) compared the spatial knowledge acquisition of GPS-based navigation systems users, physical map users, and self-experience users in an urban environment employing sketch map drawing test as a method. They measured the sketch maps in terms of topological accuracy through counting for each participant the number of routes that depicted all the turns in the correct directions and sequences. They stated that GPS users had the poorest topological accuracy of the area that they have been through. Willis et al. (2009) noted that people navigating with mobile maps were less accurate in drawing the sketch maps of the studied area and also had poor configurational knowledge. They also found that mobile map users were poor in estimating the distance travelled or the cardinal directions of landmarks they passed by. Ahmadpoor and Heath (2018) found that people who use mobile maps for navigation have poor landmark knowledge in comparison to those who experience the environment directly. Besides, they demonstrated that the characteristics of landmarks moderate landmark knowledge of both people who use mobile maps and those who do not.

\subsection{Spatial Knowledge Acquisition and Physical Environment}

One of the main factors in spatial knowledge acquisition or cognitive mapping is physical environment. Physical environment refers to any natural or man-made features of the environment. They can limit and/or facilitate people's environmental behaviour, such as navigation (Pastalan \& Carson, 1970). In this paper, the physical environment specifically is referred to the man-made/built urban environment.

Cognitive maps are the internal representation of the physical environment; 
people abstract the physical environment into cognitive representations in order to store the spatial information quickly and efficiently. Some specific elements are more imageable and can be stored easily in people's mind than others. Lynch (1960) suggested five imageable elements that comprise people's cognitive maps. He identified these elements by interviewing people and analysing their sketch maps of three different American cities. These elements are landmarks, paths, nodes, edges, and districts. After Lynch, other researchers tested Lynch's findings and confirmed the results, e.g. see (Appleyard, 1969; Appleyard, 1970; De Jonge, 1962; Francescato \& Mebane, 1973; Gulick, 1963). The importance of these spatial elements in forming the cognitive maps varies in different studies, Table 1 demonstrates these differences.

These spatial elements can be defined as follow:

1) Landmarks are reference point for the traveller/observer. These points have distinctive characteristics that contrast with background information. For example, tall buildings, historic buildings, buildings with distinctive colours (e.g. parliament building, and Big Ben in London, Washington Monument in Washington D.C.).

2) Nodes are strategic points in the physical setting which a traveler/observer can entre to. They are the rigorous foci to and from which people travel. They are mainly junctions, where there is a break in transportation, a crossing or

Table 1. Importance degree of the elements of the sketch maps according to each research's participants drawings. Adopted from Long and Baran (2012).

\begin{tabular}{|c|c|c|c|c|c|c|c|}
\hline \multirow{2}{*}{ Researcher (s) } & \multirow{2}{*}{ Cities studied } & \multirow{2}{*}{ Number of Participants } & \multicolumn{5}{|c|}{ Important Elements } \\
\hline & & & Land-mark & Node & Path & Edge & District \\
\hline Lynch (1960) & $\begin{array}{c}\text { Jersey City, } \\
\text { Los Angeles (United States) }\end{array}$ & 60 (Professional, managerial) & & & & & \\
\hline de Jonge (1962) & $\begin{array}{l}\text { Amsterdam, The Hague, } \\
\text { Rotterdam (Netherlands) }\end{array}$ & 72 (Wives of white-collar workers) & & & & & \\
\hline Gulick (1963) & Tripoli (Lebanon) & 35 (students, upper middle class) & & & & & \\
\hline Klein (1967) & Karlsruhe (Germany) & 1118 (Residents) & & & & & \\
\hline Saarinen (1969) & Chicago ( United states) & 72 (students, workers) & & & & & \\
\hline Appleyard (1969) & GiudadGuayana (Venezuela) & $\begin{array}{l}320 \text { (Residents from } \\
\text { selected settlements) }\end{array}$ & & & & & \\
\hline Blanch (1970) & $\begin{array}{l}\text { Mexico City, Puebla, Guanajuato, } \\
\text { San Cristobal las Casas (Mexico) }\end{array}$ & 769 (Residents, students) & & & & & \\
\hline $\begin{array}{c}\text { Francescato and } \\
\text { Mebane (1973) }\end{array}$ & Milan and Rome (Italy) & 183 (residents) & & & & & \\
\hline Yan (1990) & Beijing (China) & 432 (residents, professional) & & & & & \\
\hline Lynch (1984) & Theoretica & 1 arguments & & & & & \\
\hline Jacobs (1993) & Theoretica & 1 arguments & & & & & \\
\hline
\end{tabular}

Notes: $\bigcirc$ Important elem ent, Very important elem ent. 
convergence of number of paths, or moments of shift from one structure to another. Examples are a traffic square, and civic square.

3) Paths are the channels in which a traveller/observer moves usually, occasionally, or potentially. They can be streets, walkways, transit lines, canals, and railroads.

4) Edges are linear elements that act as boundaries between two phases and are linear breaks in continuity: shores, railroad cut, edges of development, and walls.

5) Districts are medium-sized subsections of the city/neighbourhood. People may entre them and feel "inside of". They can be business centre, campus, or residential neighbourhood.

The physical environment can be recognised, and remembered because of some characteristics of physical environment, such as height, significance, and unique architecture of a building, or the width of a path, or the colour of its pavement. Such properties of physical environment are "elemental", and their characteristics can be understood by only being present at the place. However, another property of the physical environment which can be only learned by moving within the physical environment is concerned with relation and organisation between places/elements of physical environment. The former, elemental properties, are termed to discrete properties (or, discrete elements) and the latter as relational properties (or relational elements) (Haq, 2003). Both types of properties comprise the cognitive maps. Evaluation is an inherent part of the spatial design disciplines and it can be applied to any planning and design decision (Shahab et al., 2017). In this vein, researchers have suggested different frameworks to evaluate the physical environment in relation to people' spatial knowledge acquisition (Appleyard, 1969; Evans et al., 1982; Passini et al., 1998; Weisman, 1981). These frameworks help to understand how the characteristics of discrete and relational properties of physical environment contribute to people's spatial knowledge acquisition.

\section{Conclusion}

Research in cognitive science has focused on how to represent the knowledge structures and processes that generate individuals' behaviour in different complex domains. In this vein, spatial cognition has become an increasingly important area of study since it represents a major type of human knowledge with considerable practical significance. The general belief is that an individual's spatial knowledge provides the basis for interpreting the objects, interactions and events in physical environment. This knowledge guides spatial decisions and behaviours of individuals in response to the perceptions and interpretations of self and physical environment. Critical issues within this area include how such knowledge is represented and organised, the mechanisms by which it is activated, and the elementary and higher-level cognitive processes that function upon the knowledge base to produce new knowledge. Also, the factors that are 
influential on acquiring this knowledge are parts of these issues. The theories in spatial knowledge acquisitions attempted to address these issues. This paper, by reviewing the literature, discussed the theories of spatial knowledge acquisition and development, and the external factors involved in this process, namely physical environment itself and means of spatial knowledge acquisition, for example mobile maps and physical maps.

\section{Conflicts of Interest}

The authors declare no conflicts of interest regarding the publication of this paper.

\section{References}

Ahmadpoor, N., \& Heath, T. (2015). The Image of the City in the Information Era. Hybrid City: Data to the People, Athens, Greece.

http://eprints.nottingham.ac.uk/55564/1/Imaging\%20City-Hybrid\%20City\%202015\%2 0-\%20Data\%20to\%20the\%20People_Conference\%20Proceedings.pdf

Ahmadpoor, N., \& Heath, T. (2017). Navigation by GPS-Based Systems: Engagement with/Disengagement from the Place and the Respective Role of Urban Design. The International Conference between Data and Senses; Architecture, Neuroscience and the Digital Worlds. London, UK. http://eprints.nottingham.ac.uk/55565/1/Between\%20Data\%20and\%20Senses.pdf

Ahmadpoor, N., \& Heath, T. (2018). Data and GPS Systems: Comparing Navigation and Landmark Knowledge between GPS Users and Non-GPS Users. In: A. Karandinou (Ed.), Data, Architecture and the Experience of Place. London: Routledge. https://doi.org/10.4324/9781351139328-9

Anderson, J. R. (1996). ACT: A Simple Theory of Complex Cognition. American Psychologist, 51, 355. https://doi.org/10.1037/0003-066X.51.4.355

Appleyard, D. (1969). Why Buildings Are Known: A Predictive Tool for Architects and Planners. Environment and Behavior, 1, 131-156. https://doi.org/10.1177/001391656900100202

Appleyard, D. (1970). Styles and Methods of Structuring a City. Environment and Behavior. https://doi.org/10.1177/001391657000200106

Beck, R. J., \& Wood, D. (1976). Cognitive Transformation of Information from Urban Geographic Fields to Mental Maps. Environment and Behavior, 8, 199-238. https://doi.org/10.1177/001391657682003

Blades, M. (1991). Wayfinding Theory and Research: The Need for a New Approach. Cognitive and Linguistic Aspects of Geographic Space. Springer.

Blanch, J. M. L. (1970). Las zonas dialectales de México: Proyecto de delimitación. Nueva Revista de Filología Hispánica, 19, 1-11.

Coors, V., Elting, C., Kray, C., \& Laakso, K. (2005). Presenting Route Instructions on Mobile Devices: From Textual Directions to 3D Visualization. Exploring Geovisualization. Elsevier. https://doi.org/10.1016/B978-008044531-1/50445-0

De Jonge, D. (1962). Images of Urban Areas Their Structure and Psychological Foundations. Journal of the American Institute of Planners, 28, 266-276. https://doi.org/10.1080/01944366208979452

Devlin, A. S. (1976). The "Small Town" Cognitive Map: Adjusting to a New Environment. 
Environmental Knowing: Theories, Research and Methods. Dowden, Hutchinson and Ross.

Dillemuth, J. (2005). Map Design Evaluation for Mobile Display. Cartography and Geographic Information Science, 32, 285-301. https://doi.org/10.1559/152304005775194773

Dogu, U., \& Erkip, F. (2000). Spatial Factors Affecting Wayfinding and Orientation: A Case Study in a Shopping Mall. Environment and Behavior, 32, 731-755. https://doi.org/10.1177/00139160021972775

Downs, R. M., \& Stea, D. (1973). Image and Environment: Cognitive Mapping and Spatial Behavior. Transaction Publishers.

Evans, G. W. (1980). Environmental Cognition. Psychological Bulletin, 88, 259. https://doi.org/10.1037/0033-2909.88.2.259

Evans, G. W., Marrero, D. G., \& Butler, P. A. (1981). Environmental Learning and Cognitive Mapping. Environment and Behavior, 13, 83-104. https://doi.org/10.1177/0013916581131005

Evans, G. W., Smith, C., \& Pezdek, K. (1982). Cognitive Maps and Urban Form. Journal of the American Planning Association, 48, 232-244. https://doi.org/10.1080/01944368208976543

Francescato, D., \& Mebane, W. (1973). How Citizens View Two Great Cities: Milan and Rome. In R. Downs \& D. Stea (Eds.), Image and Environment (pp. 131-147). Chicago: Aldine.

Gärling, T., Böök, A., Lindberg, E., \& Nilsson, T. (1981). Memory for the Spatial Layout of the Everyday Physical Environment: Factors Affecting Rate of Acquisition. Journal of Environmental Psychology, 1, 263-277. https://doi.org/10.1016/S0272-4944(81)80025-4

Gladwin, T. (1972). East Is a Big Bird. Cambridge, MA: Harvard University Press.

Golledge, R. G. (1978). Learning about Urban Environment. In T. Carlstein, D. Parkes, \& N. Thrift (Eds.), Timing Space and Spacing Time, Vol. I: Making Sense of Time (pp. 76-98). London: Edward Arnold.

Golledge, R. G. (1999). Human Wayfinding and Cognitive Maps. Wayfinding Behavior: Cognitive Mapping and Other Spatial Processes, 5-45.

Golledge, R. G., Jacobson, R. D., Kitchin, R., \& Blades, M. (2000). Cognitive Maps, Spatial Abilities, and Human Wayfinding. Geographical Review of Japan, Series B, 73, 93-104. https://doi.org/10.4157/grj1984b.73.93

Gulick, J. (1963). Images of an Arab City. Journal of the American Institute of Planners, 29, 179-198. https://doi.org/10.1080/01944366308978063

Haq, S. (2003). Investigating the Syntax Line: Configurational Properties and Cognitive Correlates. Environment and Planning B: Planning and Design, 30, 841-863. https://doi.org/10.1068/b2960

Haq, S., \& Girotto, S. (2003). Ability and Intelligibility: Wayfinding and Environmental Cognition in the Designed. In 4th International Space Syntax Symposium (pp. 68-88). Location. http://www.spacesyntax.net/symposia-archive/SSS4/fullpapers/68Haq-Girottopaper.pd f

Hart, R. A., \& Moore, G. T. (1973). The Development of Spatial Cognition: A Review. New Brunswick, NJ: Aldine Transaction.

Herman, J. F., Blomquist, S. L., \& Klein, C. A. (1987). Children's and Adults' Cognitive 
Maps of Very Large Unfamiliar Environments. British Journal of Developmental Psychology, 5, 61-72. https://doi.org/10.1111/j.2044-835X.1987.tb01042.x

Herman, J. F., Kail, R. V., \& Siegel, A. W. (1979). Cognitive Maps of a College Campus: A New Look at Freshman Orientation. Bulletin of the Psychonomic Society, 13, 183-186. https://doi.org/10.3758/BF03335054

Hirtle, S. C., \& Hudson, J. (1991). Acquisition of Spatial Knowledge for Routes. Journal of Environmental Psychology, 11, 335-345. https://doi.org/10.1016/S0272-4944(05)80106-9

Humphreys, J. (1990). Place Learning and Spatial Cognition: A Longitudinal Study of Urban Newcomers. Tijdschrift voor economische en sociale geografie, 81, 364-380. https://doi.org/10.1111/j.1467-9663.1990.tb01335.x

Ishikawa, T., \& Montello, D. R. (2006). Spatial Knowledge Acquisition from Direct Experience in the Environment: Individual Differences in the Development of Metric Knowledge and the Integration of Separately Learned Places. Cognitive Psychology, 52, 93-129. https://doi.org/10.1016/j.cogpsych.2005.08.003

Ishikawa, T., Fujiwara, H., Imai, O., \& Okabe, A. (2008). Wayfinding with a GPS-Based Mobile Navigation System: A Comparison with Maps and Direct Experience. Journal of Environmental Psychology, 28, 74-82. https://doi.org/10.1016/j.jenvp.2007.09.002

Ittelson, W. H. (1973). Environment and Cognition. Seminar Press.

Jacobs, A. B. (1993). Great Streets.

Kaplan, S., \& Kaplan, R. (1982). Cognition and Environment: Coping in an Uncertain World. New York: Praeger.

Kitchin, R. M. (1994). Cognitive Maps: What Are They and Why Study Them? Journal of Environmental Psychology, 14, 1-19.

Klatzky, R. L., Loomis, J. M., Golledge, R. G., Cicinelli, J. G., Doherty, S., \& Pellegrino, J. W. (1990). Acquisition of Route and Survey Knowledge in the Absence of Vision. Journal of Motor Behavior, 22, 19-43. https://doi.org/10.1080/00222895.1990.10735500

Klein, H. J. (1967). The Delimitation of the Town Centre in the Image of Its Citizens. Urban Core and Inner City, 286306.

Krüger, A., Aslan, I., \& Zimmer, H. (2004). The Effects of Mobile Pedestrian Navigation Systems on the Concurrent Acquisition of Route and Survey Knowledge. In International Conference on Mobile Human-Computer Interaction (pp. 446-450). Berlin: Springer.

Landau, B., Gleitman, H., \& Spelke, E. (1981). Spatial Knowledge and Geometric Representation in a Child Blind from Birth. Science, 213, 1275-1278. https://doi.org/10.1126/science.7268438

Landau, B., Spelke, E., \& Gleitman, H. (1984). Spatial Knowledge in a Young Blind Child. Cognition, 16, 225-260. https://doi.org/10.1016/0010-0277(84)90029-5

Leonard, J. A., \& Newman, R. (1967). Spatial Orientation in the Blind. Nature, 215, 1413. https://doi.org/10.1038/2151413a0

Liben, L. S., Kastens, K. A., \& Stevenson, L. M. (2002). Real-World Knowledge through Real-World Maps: A Developmental Guide for Navigating the Educational Terrain. Developmental Review, 22, 267-322. https://doi.org/10.1006/drev.2002.0545

Long, Y., \& Baran, P. K. (2012). Does Intelligibility Affect Place Legibility? Understanding the Relationship between Objective and Subjective Evaluations of the Urban Environment. Environment and Behavior, 44, 616-640.

https://doi.org/10.1177/0013916511402059 
Loomis, J. M., Klatzky, R. L., Golledge, R. G., Cicinelli, J. G., Pellegrino, J. W., \& Fry, P. A. (1993). Nonvisual Navigation by Blind and Sighted: Assessment of Path Integration Ability. Journal of Experimental Psychology: General, 122, 73.

Lynch, K. (1960). The Image of the City. Cambridge, MA: MIT Press.

Lynch, K. (1984). Good City Form. Cambridge, MA: MIT Press.

Mandler, J. M. (1988). How to Build a Baby: On the Development of an Accessible Representational System. Cognitive Development, 3, 113-136.

https://doi.org/10.1016/0885-2014(88)90015-9

Mcdonald, T. P., \& Pellegrino, J. W. (1993). Psychological Perspectives on Spatial Cognition Thomas. Advances in Psychology, 96, 47-82.

https://doi.org/10.1016/S0166-4115(08)60039-4

Montello, D. R. (1998). A New Framework for Understanding the Acquisition of Spatial Knowledge in Large-Scale Environments. In M. J. Egenhofer, \& R. G. Golledge (Eds.), Spatial and Temporal Reasoning in Geographic Information Systems (pp. 143-154). New York: Oxford University Press.

Montello, D. R., Waller, D., Hegarty, M., \& Richardson, A. E. (2004). Spatial Memory of Real Environments, virtual Environments, and Maps. Human Spatial Memory: Remembering Where, 251-285.

Moore, G. T. (1974). The Development of Environmental Knowing: An Overview of an Interactional-Constructivist Theory and Some Data on Within-Individual Development Variations. In D. V. Canter, \& T. Lee (Eds.), Psychology and the Built Environment (pp. 184-194). Hoboken, NJ: Wiley.

Münzer, S., Zimmer, H. D., Schwalm, M., Baus, J., \& Aslan, I. (2006). Computer-Assisted Navigation and the Acquisition of Route and Survey Knowledge. Journal of Environmental Psychology, 26, 300-308. https://doi.org/10.1016/j.jenvp.2006.08.001

Murray, D., \& Spencer, C. (1979). Individual Differences in the Drawing of Cognitive Maps: The Effects of Geographical Mobility, Strength of Mental Imagery and Basic Graphic Ability. Transactions of the Institute of British Geographers, 4, 385-391. https://doi.org/10.2307/622058

Passini, R., Rainville, C., Marchand, N., \& Joanette, Y. (1998). Wayfinding and Dementia: Some Research Findings and a New Look at Design. Journal of Architectural and Planning Research, 15, 133-151.

Pastalan, L. A., \& Carson, D. H. (1970). Spatial Behavior of Older People. Ann Arbor, MI: University of Michigan.

Pearce, P. L. (1977). Mental Souvenirs: A Study of Tourists and Their City Maps. Australian Journal of Psychology, 29, 203-210. https://doi.org/10.1080/00049537708255282

Piaget, J., \& Inhelder, B. (2013). The Growth of Logical Thinking from Childhood to Adolescence: An Essay on the Construction of Formal Operational Structures. London: Routledge. https://doi.org/10.4324/9781315009674

Pocock, D. C. (1976). Some Characteristics of Mental Maps: An Empirical Study. Transactions of the Institute of British Geographers, 1, 493-512. https://doi.org/10.2307/621905

Rieser, J. J., Lockman, J. J., \& Pick, H. L. (1980). The Role of Visual Experience in Knowledge of Spatial Layout. Perception \& Psychophysics, 28, 185-190. https://doi.org/10.3758/BF03204374

Roskos-Ewoldsen, B., Mcnamara, T. P., Shelton, A. L., \& Carr, W. (1998). Mental Representations of Large and Small Spatial Layouts Are Orientation Dependent. Journal of 
Experimental Psychology: Learning, Memory, and Cognition, 24, 215.

Saarinen, T. F. (1969). Preception of the Drought Hazard on the Great Plains.

Sadalla, E. K., \& Montello, D. R. (1989). Remembering Changes in Direction. Environment and Behavior, 21, 346-363. https://doi.org/10.1177/0013916589213006

Shahab, S., Clinch, J. P., \& O’neill, E. (2017). Impact-Based Planning Evaluation: Advancing Normative Criteria for Policy Analysis. Environment and Planning B: Urban Analytics and City Science. https://doi.org/10.1177/2399808317720446

Shemyakin, F. N. (1961). Orientation in Space. In B. G. Ananyev et al. (Eds.), Psychological Science in the U.S.S.R. (Vol. 1). Washington DC: Joint Publication Research Service.

Sholl, M. J. (1988). The Relation between Sense of Direction and Mental Geographic Updating. Intelligence, 12, 299-314. https://doi.org/10.1016/0160-2896(88)90028-1

Shoval, N., \& Isaacson, M. (2006). Application of Tracking Technologies to the Study of Pedestrian Spatial Behavior. The Professional Geographer, 58, 172-183. https://doi.org/10.1111/j.1467-9272.2006.00524.x

Siegel, A. W., \& White, S. H. (1975). The Development of Spatial Representations of Large-Scale Environments. Advances in Child Development and Behavior, 10, 9-55. https://doi.org/10.1016/S0065-2407(08)60007-5

Speake, J. (2015). “I've Got My Sat Nav, It's Alright”: Users' Attitudes towards, and Engagements with, Technologies of Navigation. The Cartographic Journal, 52, 345-355. https://doi.org/10.1179/1743277414Y.0000000088

Spencer, C., \& Weetman, M. (1981). The Microgenesis of Cognitive Maps: A Longitudinal Study of New Residents of an Urban Area. Transactions of the Institute of British Geographers, 6, 375-384. https://doi.org/10.2307/622295

Streeter, L. A., Vitello, D., \& Wonsiewicz, S. A. (1985). How to Tell People Where to Go: Comparing Navigational Aids. International Journal of Man-Machine Studies, 22, 549-562. https://doi.org/10.1016/S0020-7373(85)80017-1

Thorndyke, P. W., \& Hayes-Roth, B. (1982). Differences in Spatial Knowledge Acquired from Maps and Navigation. Cognitive Psychology, 14, 560-589.

https://doi.org/10.1016/0010-0285(82)90019-6

Walmsley, D., \& Jenkins, J. M. (1992). Tourism Cognitive Mapping of Unfamiliar Environments. Annals of Tourism Research, 19, 268-286.

https://doi.org/10.1016/0160-7383(92)90081-Y

Weisman, J. (1981). Evaluating Architectural Legibility: Way-Finding in the Built Environment. Environment and Behavior, 13, 189-204.

https://doi.org/10.1177/0013916581132004

White, S. H. (1983). The Idea of Development in Developmental Psychology.

Willis, K. S., Hölscher, C., Wilbertz, G., \& Li, C. (2009). A Comparison of Spatial Knowledge Acquisition with Maps and Mobile Maps. Computers, Environment and Urban Systems, 33, 100-110. https://doi.org/10.1016/j.compenvurbsys.2009.01.004

Worchel, P. (1951). Space Perception and Orientation in the Blind. Psychological Monographs: General and Applied, 65.

Yan, X. (1990). Human Impacts of Changing City Form: A Case Study of Beijing. Unpublished Doctoral Dissertation. Ann Arbor: The University of Michigan. 